УДК 372.881.111.1

DOI: $10.33184 /$ psrvoyap. 25

Мисикова Бела Гадагкоевна, Салбиева Литасфера Зелимхановна Северо-Осетинский государственный университет им. К.Л. Хетагурова misikova.bela@mail.ru; elizaveta.mamaeva.2016@mail.ru

\title{
МЕЖПРЕДМЕТНАЯ ИНТЕГРАЦИЯ - ВАЖНЕЙШИЙ ПРИНЦИП ОБУЧЕНИЯ РУССКОМУ ЯЗЫКУ В ПОЛИЭТНИЧЕСКОЙ СРЕДЕ СОВРЕМЕННОЙ ШКОЛЫ
}

Аннотация: Привлечение материала языковых связей, являющееся одним из резервов повышения эффективности преподавания русского языка в полиэтнической среде современной школы, развивает самостоятельность обучаемых, активизирует их познавательную деятельность, открывает широкие возможности для межпредметной интеграции, которая является важным условием современного образования.

В статье впервые показана роль интегрированного обучения в осетинской школе. Обращение к фактам осетинского и русского языков в их сопоставлении создает лингвистическую базу для учебных занятий и по осетинскому, и по русскому языкам в полиэтнической среде. Более того, опора на знание русского языка чрезвычайно облегчает и усвоение осетинского языка, который учащиеся-осетины теперь порой знают хуже, чем русский. Приведенные в данном исследовании положения представляют интерес для методистов-осетиноведов и могут быть применены во многих полиэтнических регионах Российской Федерации.

Ключевые слова: осетинский язык, русский язык, интеграция, полиэтническая среда, сопоставление, определенноличные предложения.

Межпредметная интеграция в полиэтнической среде сегодня важнейший фактор развития образования. Только использование межпредметных и интегральных связей в обучении помогает учителю сформировать у учащихся целостную картину мира. 
В национальных школах XXI века особое значение приобретают вопросы национально-языковой политики, основными принципами которой были и остаются свободное развитие и равноправие всех языков, добровольный выбор языка обучения. При этом следует отметить, что обучение родному языку не изолируется, не противопоставляется обучению русскому языку, а рассматривается как единый процесс развития мыслительной деятельности учащихся с естественной реализацией на двух языках: родном и русском, что позволяет сформировать у учащихся-осетин компетенцию, связанную с переносом знаний, умений и навыков с одного учебного предмета на другой. Более того, учащиеся, изучая два языка во взаимосвязи, сравнивают их, целенаправленно усваивают формы и способы формирования мысли. Такая ситуация в учебном процессе дает возможность учащимся познать общие законы формирования языков, универсальный характер языковых категорий, «формирование обобщенных межпредметных умений, обладающих свойством широкого переноса» [Мирзаева, Гаджиев 2013, с. 65].

Необходимость такого исследования обусловлена существующей практикой национальных школ Республика Северная Осетия-Алания, в которых изучаемые языки (русский и осетинский) рассматриваются отдельно, без осуществления необходимых объективных связей. При этом остается в стороне происходящее в сознании учащихся-осетин взаимодействие двух языковых систем.

Двуязычностью осетинской школы обусловливается потребность учащихся-осетин в овладении русским языком, ибо без его знания не происходит в их среде понимания и взаимообогащения.

Одновременное изучение родного и русского языков в осетинской школе и ознакомление с накопленным в этой области опытом методических исследований приводит нас к выводу о том, что сравнение осетинского языка с русским необходимо как на уровне лингвистического анализа языкового материала, так и в собственно методической его обработке.

Практическая реализация сказанного позволяет многие вопросы синтаксиса осетинского языка изучать не как новые темы, 
a как применение теоретических знаний по русскому языку к материалу осетинского языка или наоборот. Внедрение в учебный процесс такой дидактической концепции возможно только на основе фактов осетинского и русского языков, т.к. они дают возможность эффективного их преподавания.

Исследуемый материал следует изучать в сравнительносопоставительном аспекте. Из всего материала синтаксиса, используя знания учащихся-осетин по русскому языку, в данной работе рассматриваем лишь те вопросы, которые являются наболее важными для раскрытия практического значения исследуемой проблемы в школах нашего региона. Более того, изучение данных синтаксических конструкций имеет немаловажное значение для обучения, для определения специфики грамматического строя осетинского языка. В данной работе рассматриваются словосочетание и простое предложение.

Изучение словосочетания (как и других тем курса осетинского языка на всех этапах) проводится вне всякой связи со знаниями, умениями и навыками, полученными и сформированными на уроках русского языка. Поэтому можно предложить конструкции русского языка (распространенные и нераспространенные предложения), показывающие функционирование словосочетания в составе предложения и помогающие понять его отличие от предложения и слова. При этом надо учитывать и тот факт, что в осетинском языке много составных глаголов, предложных и послеложных сочетаний, которые входят в состав словосочетаний и предложений, например: хъсер ксннын «кричать», сенхъселмсе ксесын «ждать», хсезары иур «возле дома», горсты скрмсе «над городом» и т.д. Чтобы представить словосочетание как грамматическое явление, можно использовать знания по русскому языку, в частности схему грамматического разбора русских словосочетаний: 1) определить главное и зависимое слово; 2) поставить вопрос от главного слова к зависимому; 3) определить, какими частями речи выражены главное и зависимое слово; 4) объяснить, с помощью каких грамматических средств оформлена связь зависимого слова от главного. 
Принцип последовательности и перспективности в изучении осетинского языка требует продолжения работы над словосочетанием в связи с изучением частей речи в курсе морфологии, поскольку в состав словосочетаний может входить любая часть речи. Можно рассматривать каждую часть речи в составе словосочетания как в качестве главного, так и в качестве зависимого компонента. Такую работу рекомендуется проводить при выполнении различных заданий по закреплению материала о формах и категориях изучаемых частей речи и направленных на речевое развитие.

В результате проводимой таким образом практической работы обеспечивается необходимая повторяемость изученных синтаксических единиц, типов словосочетаний, активизируется лексика и учащиеся-осетины усваивают основные особенности структуры словосочетаний осетинского языка.

Основное внимание сосредоточивается на выяснении способов образования словосочетаний путем управления и примыкания. Привлечение русского языка на этом этапе работы осуществляется на уровне теоретическом (используются полученные ранее на уроках русского языка теоретические знания правил, определений) и на уровне практическом (используются сформированные ранее грамматические и речевые умения и навыки).

Учет теоретических знаний учащихся-осетин о том, что выражает слово, словосочетание и предложение в русском языке, и привлечение этих знаний помогут расширить и углубить аналогичные знания по осетинскому языку. Используя сравнительно-сопоставительный метод с привлечением примеров на русском и осетинском языках, можно добиться самостоятельного определения учениками предложения как речевой единицы, сообщающей что-либо о предмете (в отличие от словосочетания, которое только называет предмет или признак, действие), произносимой с интонацией законченности, в то время как словосочетание не обладает такой интонацией. Например:

1. Анусон иъъти авгау серттивы хуры рухсмо / Вечнылй ледник сверкает далеко, как стекло, на солнце. 
2. Анусон изъити, артттивы авгау, серттивы рухсмсе, серттивы дард, хуры рухсмсе / Вечный ледник, сверкает далеко, сверкает как стекло, сверкает на солнще.

В обоих языках слова, из которых состоят словосочетания, находятся в определенных смысловых отношениях между собой, отражающих существующие в реальной действительности отношения между явлениями. «Семантика словосочетаний обусловлена взаимодействием лексических и грамматических значений главного и зависимого компонентов при доминирующем влиянии последнего» [СРЯ 2007].

Для словосочетаний осетинского и русского языков аналогичными являются виды подчинительной связи: управление и примыкание. При управлении главное слово требует постановки подчиненного слова в каком-либо падеже с предлогом или без предлога [Валгина 2006, Цопанова 2001]. Например: Лкеnу ащьыдис уынгмсе сед пурти. - Лсеппу ацылди уынгмсе пуртиимсе (Мальчик вылел на улииу с мячом). В осетинском варианте объект пурти «мяч» может стоять в именительном падеже, так как этого требует подчиняющее слово глагол аџыдис через предлог се «с», а без предлога сед существительное пурти было бы поставлено в союзном падеже (а в русском варианте в творительном падеже): Лсепу ацььдис уынгмсе пуртиимхе.

Сходной является в обоих языках и связь примыкание. В предложении Даргъ зымкег ивгсейс, хъазгсе, сетттивгсейсе, ралсууыл бон [Гулуев 1968] «Сменяя долгую зиму, играя, сверкая, наступил день» слова-деепричастия ивгсейсе, хъазгсе, жрттивгжйхе связаны с подчиняющим словом - глаголом ралсууыд посредством примыкания: как бы ни изменяли форму подчиняющего слова (в лице, числе, наклонении, времени), деепричастия ивгсейж, хъазгсе, серттивгсейсе будут оставаться без изменения.

В рассматриваемых языках - русском и осетинском словосочетания имеют грамматическую форму и собственное грамматическое значение: главное, стержневое слово в именном и глагольном словосочетаниях может изменяться, как и отдельное слово: скъоладзауы чиныг (книга ученика), скъоладзауы чиныджы (в книге ученика), скъоладзауы чиныгаен (книге ученика), скъоладзауы чингуытыл (на книгах ученика); каесын чиныг (читаю 
книгу), ксесыс чиныг (читаешь книгу), каесы чиныг (читает книгу), каесынич чиныг (читают книгу).

Словосочетания в обоих языках классифицируются по морфологической принадлежности главного компонента (глагольные, именные, наречные), по количеству компонентов (простые и сложные).

Такое обращение к фактам русского и осетинского языков в их сопоставлении, педагогический умелый подход к общим, близким и дифференциальным чертам родного и русского языков создает достаточно прочную и эффективную лингвистическую базу для учебных занятий и по осетинскому, и по русскому языкам, значительно обогащая их фактическим материалом, делая их более занимательными и эффективными в лингвистическом плане. Если уже известное относится к смежной учебной дисциплине, то, на наш взгляд, тем ценнее его использование, так как осуществление межпредметных связей расширяет мыслительную деятельность учащихся, помогает овладеть приемами анализа и синтеза.

Привлечению знаний учащихся-осетин по русскому языку помогают сопоставление примеров, объяснение и вопросы учителя, стимулирующие воспроизведение усвоенного ранее: вспомните, что показывают, например, словосочетания читаю книгу, говорил тихо в русском языке? Чем отличаются словосочетания говорил тихо и отец говорил тихо и т.д.

Взаимосвязь преподавания осетинского и русского языков требует учета сформированных на уроках умений и навыков и опоры на эти умения. Как уже отмечалось выше, поскольку учебный план и программа отводят на изучение русского языка значительно большее количество часов, большинство грамматических тем, имеющих аналогию и в осетинском языке, изучаются на уроках русского языка раньше или же одновременно.

Следовательно, многие умения и навыки формируются на уроках русского языка раньше. Так, например, учащиеся-осетины к 8-му классу достаточно хорошо владеют следующими умениями: составлять словосочетания, устанавливать связь слов в предложении по вопросам, включать в речь отдельные типы словосочетаний. Учащиеся данной возрастной группы владеют, 
правда в различной степени, и такими речевыми навыками, как нахождение в тексте синонимичных словосочетаний, замена данного словосочетания синонимичным. Используя имеющиеся умения и навыки по русскому языку, ученикам можно предложить выполнить ряд упражнений на материале словосочетаний, например:

1) составление словосочетаний из отдельных слов (чиньг, фарс - чиньлжжы фарс; скъоладзау, кърандасскъоладзауьл кърандас);

2) подбор к данным синонимичным глаголам зависимых слов и составление с ними предложений: (цсеуын) -

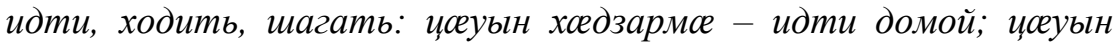
скъоламсе - ходить в школу, цскуын роехъы - шагать в строю; (дзурын) - говорить, заявлять, сообщзать, высказывать: дзурын роестдзинад (говорить правду); хабар фехъусын конилн (сообщить весть); хи хъуылдытсе дзурын (высказать свое мнение) и т.д.

Такая работа помогает закреплять знания, совершенствуя навыки выделения, составления, оформления грамматической связи главного и зависимого слов, подготавливает учеников к пониманию способов грамматической связи слов в словосочетании в осетинском языке.

Наибольшую трудность при изучении простого предложения осетинского языка составляют односоставные предложения.

Лингвистический анализ определенно-личных предложений осетинского и русского языков, сопоставление структурных, семантических и функциональных его признаков показал, что определения определенно-личных предложений в осетинском и русском языках аналогичны. Исходя из определений в обоих языках сказуемое в определенно-личных предложениях выражается формами 1-2 лица единственного и множественного числа повелительного наклонения без личных местоимений $Я$ Ä3, $M b l-M a x, T b l-Д b l, B b l-C b l м a x$.

Для более доступного объяснения названных видов односоставных предложений, внимание учащихся-осетин можно обратить на то обстоятельство, что способ выражения сказуемого оказывает свое влияние на значение предложения. А этот процесс 
убедительнее проявляется при сопоставлении определенно-личных предложений с двусоставными. При этом следует подсказать учащимся, что смысловые различия в них незначительны: в определенно-личных предложениях в форме главного члена предложения (сказуемого) «заключается указание на вполне определенное лицо» [Багаев 1982, Валгина 2006]; в двусоставных предложениях обращается внимание, помимо сказанного, и на производителя действия. Для закрепления указанных выводов в данном исследовании в качестве примера предлагаются грамматико-стилистические упражнения типа: 1. Передайте от первого лича содержание любого сказания, используя при этом определенно-личные предложения. 2. Подберите из Нартских сказаний примеры односоставньх и двусоставных предложений с глаголами-сказуемыми в форме 1-го и 2-го лища. Объясните, почему в каждом случае уместнее употребить именно эту синтаксическую конструкцию. 3. Переведите данные определенноличные предложения с русского языка на осетинский:

1. Дай мне войско лучников.

2. Сделайте мне гроб и бросьте в море.

3. Подожди, ведь еще не ночь.

4. Проведаем еще ущелье Тар [Нарты 1990].

Рассмотрение русского и осетинского языков в их взаимосвязи обеспечивает координированное развитие мышления обучаемых за счет создания «сквозного» изучения сходных грамматических явлений, применения единых методических подходов к преподаванию предметов филологического цикла. Так, например, в определенно-личных предложениях русского языка частица -ка, присоединяемая к формам повелительного наклонения для смягчения повеления и придания высказыванию оттенка непринужденности, по своим семантическим и стилистическим особенностям совпадает с частицей -ма иронского диалекта: Выгляни-ка к нам наружу. - Раксес-ма нсем седдемсе.

Подобная картина наблюдается и с русской частицей -ка, которой в дигорском диалекте по семантике соответствует суффикс -га: Иди-ка и убери эту собаку. - Цогсе семсе куйи бафснайое. 
Процесс межъязыкового переноса при изучении определенно-личных предложений можно проиллюстрировать и в том случае, когда в указанных конструкциях употребляются сопутствующие главному члену слова, выражающие различные оттенки волеизъявления говорящего. Как известно, в русском языке ими являются в определенно-личных предложениях наречия: быстро, поскорей, побыстрей и т.д, модальные слова и словосочетания: действительно, верно, само собою и т.д.; в осетинском языке наречия: тагъд, тагъддар, равдз, равдздар и т.д., модальные слова и словосочетания: хуыциауы тыххай, да хорзахай: Быстрее закали меня, не то вылезу отсюда и голову тебе оторву. - Тагъд мсе байскрд, сендкра ардыгсей куы рахизон, усед дын де къубал сыскъуындзынсен.

Апробация указанных приемов работы в полиэтнической среде при изучении односоставных предложений (на примере определенно-личных предложений) позволила нам прийти к такому выводу в сложившейся методической системе, что применение сравнительно-сопоставительного метода позволяет повысить уровень усвоения изучаемого синтаксического материала учащимися-осетинами. Использование приема переноса знаний одного предмета при усвоении другого помогает учащимся-билингвам целенаправленно решать определенные задачи, повышает активность учеников, обеспечивает лучшую организацию мыслительной деятельности и, наконец, вырабатывает логическую последовательность в решении как общих, так и частных задач.

Используя русский язык при объяснении того или иного синтаксического явления осетинского языка, мы обеспечиваем активную мыслительную деятельность учащихся в процессе восприятия материала, даем тот «ориентировочный рефлекс», то «деятельное состояние коры», которое необходимо, как отмечал академик И.П. Павлов, для того, чтобы «ассоциация произошла» [Павлов 1950]. Этот «ориентировочный рефлекс» и должен выразиться в данном случае в движении внимания учащихсяосетин от фактов и явлений русского языка к явлениям родного осетинского языка. А движение внимания от родного языка к фактам русского происходит при непосредственным участии внутренней речи индивида, потому что «внутренняя речь учащихся 
является одним из основных условий сознательного (но не интуитивного) усвоения ими основ наук в общеобразовательной средней школе» [Карпов 1954, с. 48-54]

Таким образом, необходимость проведения межпредметных связей в полиэтнической среде заключена в самой природе мышления, диктуется объективными законами высшей нервной деятельности и законами психологии. Межпредметные связи служат приемом мыслительной деятельности, их следует понимать как систему синтеза и обобщения в решении познавательных задач.

В обучении важно не только сообщение или указание на уже известный материал, а приучение учащихся самостоятельно находить ранее известное, сопоставлять и соотносить вновь с тем, что уже изучено. Более того, опора на знания учащихся-осетин по русскому языку, использование их прежнего лингвистического опыта способствует более быстрому усвоению соответствующих закономерностей осетинского языка, экономит учебное время, дает возможность установить правильное соотношение теории и практики на уроках осетинского языка.

\section{Литература:}

1. Багаев Н.К. Современный осетинский язык. Ч.2. Орджоникидзе: Ир, 1982. - 492 с.

2. Валгина Н.С., Розенталь Д.Э., Фомина М.И. Современный русский язык. - М.: Логос, 2006. - 528 с.

3. Гулуев А. Осень моя. Орджоникидзе: Ир, 1968. - 172 с.

4. Мирзаева М.М., Гаджиев Г.М. Использование метода проектов при подготовке интегрированного урока // Известия Дагестанского педагогического университета. Педагогические науки. 2013, №4. - С. 65.

5. Нарты. Осетинский героический эпос в трех книгах. Книга 1. - М.: Просвещение, 1990.

6. Карпов И.В. Психологические основы методики развития речи учащихся // Развитие речи учащихся в процессе обучения в средней школе. - М.: 1954. 
7. Павлов И.П. Избранные труды. - Москва: Учпедгиз, 1950. $-616 \mathrm{c}$.

8. Современный русский язык / Под ред. П.А. Леканта. М.: Дрофа, 2007. -557 c.

9. Цопанова Р.Г., Качмазова И.С. Синтаксис современного осетинского языка. - Владикавказ: СОГУ, 2001. $204 \mathrm{c}$.

\title{
INTERDISCIPLINARY INTEGRATION AS THE KEY PRINCIPLE OF TEACHING RUSSIAN IN A MULTI-ETHNIC ENVIRONMENT OF A MODERN SCHOOL
}

\author{
(C) B.G. Misikova, \\ L.Z. Salbieva \\ North Ossetian State University \\ 46 Vatutina, 362025 Vladikavkaz, Russia. \\ Phone: +7 (8672) 53-49-52. \\ E-mail: misikova.bela@ mail.ru; \\ elizaveta.mamaeva.2016@mail.ru
}

The use of language communication materials, which are one of the reserves for improving the effectiveness of teaching Russian in a multi-ethnic environment of a modern school, develops the independence of students, activates their cognitive activity, and opens up wide opportunities for interdisciplinary integration - as a necessary condition for modern education.

This article shows for the first time the role of integrated learning in the Ossetian school. The Russian and Ossetian language facts in their comparison create an effective linguistic basis for teaching both Ossetian and Russian languages in a multi-ethnic environment. Russian will also greatly facilitate the assimilation of the Ossetian language, which Ossetian students now sometimes know less well than Russian. The provisions presented in this study will be of interest not only for methodologists-Ossetians, since the same national-language situation is observed in many regions of the Russian Federation.

Keywords: Ossetian language; Russian language; integration; multi-ethnic environment, comparison; definitely-personal sentences. 